\title{
Clinical effectiveness of house dust mite immunotherapy in mono- versus poly-sensitised patients with allergic rhinitis: a systematic review and meta-analysis*
}

\author{
Jin Youp Kim ${ }^{1,2}$, Doyeon Hwang ${ }^{3}$, Myoung-jin Jang ${ }^{4}$, Chae-Seo Rhee ${ }^{5,6,7,8}$, \\ Doo Hee Han ${ }^{5}$ \\ ' Department of Otorhinolaryngology-Head and Neck Surgery, Ilsan Hospital, Dongguk University, Goyang, Gyeonggi, Korea \\ ${ }^{2}$ Interdisciplinary Program of Medical Informatics, Seoul National University College of Medicine, Seoul, Korea \\ ${ }^{3}$ Department of Internal Medicine and Cardiovascular Center, Seoul National University Hospital, Seoul, Korea \\ ${ }^{4}$ Medical Research Collaborating Center, Seoul National University Hospital, Seoul, Korea \\ ${ }^{5}$ Department of Otorhinolaryngology, Seoul National University College of Medicine, Seoul, Korea \\ ${ }^{6}$ Graduate School of Immunology, Seoul National University College of Medicine, Seoul, Korea \\ ${ }^{7}$ Institute of Allergy and Clinical Immunology, and ${ }^{8}$ Sensory Organ Research Institute, Seoul National University Biomedical \\ Research Center, Seoul, Korea
}

Rhinology 59: 4, 352 - 359, 2021

https://doi.org/10.4193/Rhin20.588

* Received for publication:

November 19, 2020

Accepted: April 6, 2021

\begin{abstract}
Selecting an appropriate allergen-specific immunotherapy (AIT) regimen for polysensitised allergic rhinitis (AR) patients is challenging for clinicians. Although previous studies showed comparable effectiveness of single-allergen AIT with house dust mite (HDM) extract between monosensitised and polysensitised AR patients, there is no systematic review and meta-analysis demonstrating the comparable effectiveness of HDM AIT. In this meta-analysis, we analysed nine studies to compare the clinical effectiveness of HDM AIT. The primary outcome was nasal symptom score and secondary outcomes were medication and quality of life scores. The changes in nasal symptom score after HDM AIT did not significantly differ between monosensitised and polysensitised patients. The clinical effectiveness of HDM AIT regarding medication and quality of life score was not significantly different between monosensitised and polysensitised patients). In conclusion, single-allergen AIT with HDM extract showed comparable clinical effectiveness between polysensitised and monosensitised patients with AR.
\end{abstract}

Key words: allergen immunotherapy, allergic rhinitis, house dust mites, immunologic desensitisation, meta-analysis

\section{Introduction}

Allergen-specific immunotherapy (AIT) has been administered for several decades as an established treatment option for allergic rhinitis (AR) to alter the underlying immunologic mechanism. Subcutaneous immunotherapy (SCIT), a conventional form of immunotherapy, and sublingual immunotherapy (SLIT) are the most commonly prescribed forms of immunotherapy. Although the efficacy of AIT has been reported in numerous studies, including systematic review and meta-analysis ${ }^{(1-5)}$, selecting the proper regimen for AIT is still controversial ${ }^{(6-10)}$. Because AIT targets specific allergens, the ideal candidate for AIT is an AR patient sensitised to a single allergen; furthermore, the effectiveness of single-allergen AIT (AIT with a single-allergen extract) has been well demonstrated in previous studies (11-13). However, about $70-80 \%$ of AR patients are sensitised to more than one allergen in practice ${ }^{(14,15)}$, and selecting the most appro- priate AIT regimen in polysensitised AR patients is challenging. Considering the mechanism of AIT that modifies the immunologic response to a specific allergen, multiple-allergen AIT (AIT with multiple-allergen extracts) seems to be a better treatment option for polysensitised AR patients than single-allergen AIT, and some clinicians prefer to perform immunotherapy with multiple allergens, which is common in USA ${ }^{(16)}$. Distinguishing between polysensitisation and polyallergy is crucial when prescribing AIT with multiple allergens. Polysensitised patients do not necessarily have polyallergy. However, determining if these patients are polyallergic or monoallergic is not an easy task for physicians. The period during which the symptoms occur (e.g. spring for tree pollens) is most commonly used to evaluate polysensitized patients, although nasal challenge tests or component-based diagnostics are sometimes used ${ }^{(17)}$. However, determining polyallergy through medical history is not always 
accurate. Therefore, some physicians prescribe AIT for all allergens identified in a skin prick test ${ }^{(17)}$. For this reason, multipleallergen AIT in a polysensitised patient is not always effective, and the superiority of multiple-allergen AIT to single-allergen AIT has been questioned. Although a previous systematic review by Nelson showed the clinical efficacy of multiple-allergen AIT, its superiority was not clearly demonstrated ${ }^{(18)}$. In addition, the higher cost and limited response to multiple-allergen treatment should be considered when selecting multiple-allergen AIT ${ }^{(19)}$. Several studies show a comparable effectiveness of singleallergen AIT between monosensitised and polysensitised AR patients ${ }^{(20-25)}$. For grass pollen allergen, large double-blind placebo-controlled clinical trials show that the benefits of SLIT with single-allergen grass pollen in polysensitised patients are comparable to those in monosensitised patients ${ }^{(3,20)}$. However, most lines of supporting evidence on a comparison of the clinical effectiveness of single-allergen AIT with house dust mite (HDM) extracts in AR patients polysensitised or monosensitised to HDM, are reported in observational studies ${ }^{(21-29)}$, and there is a lack of systematic reviews and meta-analyses to demonstrate the clinical effectiveness of HDM AIT in polysensitised patients compared to monosensitised patients. This systematic review and meta-analysis aimed to compare the clinical effectiveness of single-allergen HDM AIT in AR patients polysensitised or monosensitised to HDM.

\section{Materials and methods}

Search strategy

A comprehensive search was conducted of the PubMed, Cochrane Library, and EMBASE databases in accordance with the Preferred Reporting Items for Systematic Reviews and MetaAnalyses (PRISMA) guideline to identify all relevant studies of AIT with single-allergen extract in monosensitised and polysensitised patients up to March 26th, $2020^{\left({ }^{30}\right)}$. Two investigators (J.Y.K. and D.H.H.) independently conducted the literature search to identify all available studies using the terms: ('rhin ${ }^{* \prime} O R$ 'allerg*') AND polysensi* AND ('immunotherapy' OR 'desensitisation' OR 'immunologic'). Only studies published in English were considered.

\section{Selection of studies}

The two investigators independently screened all abstracts and titles to identify candidate studies and discarded studies that did not satisfy the eligibility criteria; then, eligibility was determined by reviewing the full text. The eligibility criteria for the systematic review and meta-analysis were as follows: 1) the clinical effectiveness of AIT in nasal symptom scores and/or an additional symptom score was directly compared between monosensitised and polysensitised AR patients. 2) single-allergen AIT with HDM extracts was performed in monosensitised and polysensitised patients. Studies in which different doses of AIT were administered to participants and studies lacking full text (e.g. only abstracts) were excluded.

\section{Data extraction}

Data were extracted into standardised forms and independently confirmed by the two investigators. For each article, information on the following aspects was noted: the name of the first author, publication year, study design, form of AIT, age group (children or/and adults), treatment duration and maintenance dose, assessed outcome, total sample size, and the number of monosensitised and polysensitised patients. As we evaluated the clinical effectiveness of AIT through the changes in clinical outcomes, the mean and standard deviation (SD) values of each of the baseline and post-treatment clinical outcome were obtained from articles included in the meta-analysis. We sent an e-mail message to the corresponding author of articles in which the mean and SD of clinical outcome scores of the study were not reported to acquire these values. The risk of bias was evaluated according to the Newcastle-OttawaScale ${ }^{(31)}$. Study quality was evaluated on three domains independently by the two investigators: selection of study groups, comparability of groups, and ascertainment of exposure/outcome.

\section{Statistical analysis}

The primary outcome was nasal symptom score, and the secondary outcomes were medication score and quality of life score. The standardised mean difference (SMD) was the measure of effect because the included studied used different scoring systems and measures. The clinical effectiveness of AIT was evaluated by the change in nasal symptom score from baseline.

For studies presenting the means and SDs only in figures, means and SDs were drawn from figures. For studies reporting median and interquartile, mean and SD were estimated using an equation ${ }^{(32)}$. For studies without SDs of score change from baseline to post-treatment but with SDs of score at each time, the SDs of score change were imputed by using SDs of score at each time and a within-subject correlation of $0.5^{(33,34)}$. A random-effects model was used to calculate pooled effect estimates with $95 \%$ confidence intervals $(\mathrm{Cl})$. Statistical heterogeneity between the studies was assessed with the Cochran Q statistic test and the $I^{2}$ statistics. $I^{2}$ values of $25 \%, 50 \%$, and $75 \%$ have been suggested to be indicators of low, moderate, and high heterogeneity, respectively ${ }^{(33)}$. The difference in the clinical effectiveness of AIT between monosensitised and polysensitised groups was evaluated in a subgroup analysis. A sensitivity analysis was conducted to assess the influence of an individual study on the results by omitting one study in each turn. A funnel plot and Egger's test based on SMD and sample size-based precision estimate (the inverse of the square root of sample size) ${ }^{(35)}$ were used to assess the possibility of publication bias within each group for the primary outcome and not for the secondary outcomes because 


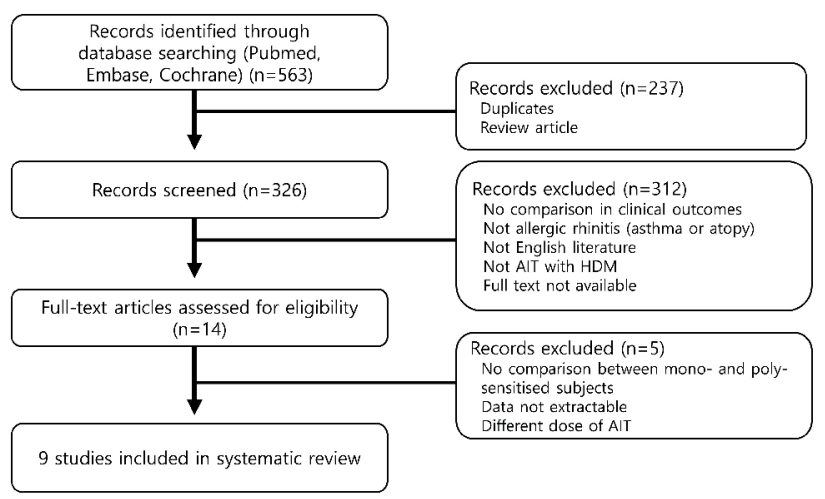

Figure 1. Flowchart of the study selection process. Abbreviations: AIT, allergen-specific immunotherapy; HDM, house dust mite.

of the small number of studies included $(n<5)$. All analyses were conducted with meta and metaphor packages in $\mathrm{R}$ version 3.6.1 (R Foundation for Statistical Computing, Vienna, Austria).

\section{Results}

Briefly, of the 563 citations identified initially through the search strategy, we finally included nine for the systematic review (Figure 1).

\section{Study characteristics}

The characteristics of the nine included studies are summarised in Table 1. The total sample size of the nine studies was 823 patients, including 411 monosensitised and 412 polysensitised patients. All were observational studies, of which four used SCIT and five used SLIT. In the included studies, patients sensitised to HDM with or without other allergens were treated with singleallergen AIT with HDM extracts. There were seven prospective cohort studies and two retrospective cohort studies. The duration of AIT ranged from 5 months to 3 years. The risk of bias for all studies was assessed using the Newcastle-Ottawa Scale.

Table 1. Summary of studies included in the meta-analysis.

\begin{tabular}{|c|c|c|c|c|c|c|c|c|c|c|}
\hline Study & Study design & $\begin{array}{l}\text { Type } \\
\text { of AIT }\end{array}$ & $\begin{array}{l}\text { Parti- } \\
\text { cipants }\end{array}$ & $\begin{array}{l}\text { Diag- } \\
\text { nosis }\end{array}$ & $\begin{array}{c}\text { Treatment duration } \\
\text { and maintenance } \\
\text { dose }\end{array}$ & $\begin{array}{l}\text { Outcome } \\
\text { assessed }\end{array}$ & $\begin{array}{c}\text { Total } \\
\text { (n) }\end{array}$ & $\begin{array}{l}\text { Mono- } \\
\text { sensi- } \\
\text { tised } \\
\text { (n) }\end{array}$ & $\begin{array}{l}\text { Poly- } \\
\text { sensi- } \\
\text { tised } \\
\text { (n) }\end{array}$ & $\begin{array}{l}\text { The Newcastle-Ot- } \\
\text { tawa Scale (NOS) }\end{array}$ \\
\hline $\begin{array}{l}\text { Lee, } \\
2011^{(21)}\end{array}$ & $\begin{array}{l}\text { Prospective } \\
\text { cohort }\end{array}$ & SLIT & $\begin{array}{l}\text { Children } \\
\text { and adults }\end{array}$ & $\begin{array}{l}\text { R w or } \\
\text { w/o A }\end{array}$ & $\begin{array}{l}1 \text { year, } 5 \text { drops of a } \\
1,000 \text { STU/mL per } \\
\text { day }\end{array}$ & TNSS, AMS & 133 & 70 & 63 & $\begin{array}{l}\text { Selection: }{ }^{* * *} \\
\text { comparability: } 0 \\
\text { Outcome: }{ }^{*}\end{array}$ \\
\hline $\begin{array}{l}\text { Kim, } \\
2014^{(26)}\end{array}$ & $\begin{array}{l}\text { Prospective } \\
\text { cohort }\end{array}$ & SCIT & Adults & $\begin{array}{l}\text { R w or } \\
\text { w/o A }\end{array}$ & 2 years, unknown & $\begin{array}{l}\text { TNSS, TMS, } \\
\text { RQLQ }\end{array}$ & 60 & 30 & 30 & $\begin{array}{l}\text { Selection: }{ }^{* * *} \\
\text { comparability: } 0 \\
\text { Outcome: }{ }^{*}\end{array}$ \\
\hline $\begin{array}{l}\mathrm{Li}, \\
2014^{(23)}\end{array}$ & $\begin{array}{l}\text { Prospective } \\
\text { cohort }\end{array}$ & SLIT & Children & $\mathrm{R} w \mathrm{~A}$ & $\begin{array}{l}1 \text { year, } 3 \text { drops of } \\
333 \mu \mathrm{g} / \mathrm{mL} \text { per day }\end{array}$ & TNSS, TMS & 112 & 56 & 56 & $\begin{array}{l}\text { Selection: }{ }^{* * *} \\
\text { comparability: } 0 \\
\text { Outcome: }{ }^{*}\end{array}$ \\
\hline $\begin{array}{l}\text { Soyyigit, } \\
2016^{(24)}\end{array}$ & $\begin{array}{l}\text { Prospective } \\
\text { cohort }\end{array}$ & SCIT & Adults & $\begin{array}{l}\text { R w or } \\
\text { w/o A }\end{array}$ & $\begin{array}{l}5 \text { months, } 100,000 \\
\text { SQ/mL per month }\end{array}$ & $\begin{array}{l}\text { TSS, TMS, } \\
\text { VAS, AQLQ, } \\
\text { RQLQ }\end{array}$ & 43 & 19 & 24 & $\begin{array}{l}\text { Selection: }{ }^{* * *} \\
\text { comparability: } 0 \\
\text { Outcome: }{ }^{*}\end{array}$ \\
\hline $\begin{array}{l}\text { Song, } \\
2018^{(25)}\end{array}$ & $\begin{array}{l}\text { Prospective } \\
\text { cohort }\end{array}$ & SCIT & children & $\begin{array}{l}\text { R w or } \\
\text { w/o A }\end{array}$ & $\begin{array}{l}3 \text { years, } 100,000 \\
\text { SQ-U per } 6 \text { weeks }\end{array}$ & VAS, RQLQ & 106 & 89 & 17 & $\begin{array}{l}\text { Selection: }{ }^{* * *} \\
\text { comparability: } 0 \\
\text { Outcome: }{ }^{* *}\end{array}$ \\
\hline $\begin{array}{l}\text { Tu, } \\
2018\end{array}$ & $\begin{array}{l}\text { Prospective } \\
\text { cohort }\end{array}$ & SCIT & $\begin{array}{l}\text { Children } \\
\text { and adults }\end{array}$ & $\begin{array}{l}\text { R w or } \\
\text { w/o A }\end{array}$ & $\begin{array}{l}2 \text { years, } 100,000 \\
\text { SQ-U per } 6 \text { weeks }\end{array}$ & TNSS & 58 & 35 & 23 & $\begin{array}{l}\text { Selection: }{ }^{* * *} \\
\text { comparability: } 0 \\
\text { Outcome: }{ }^{*}\end{array}$ \\
\hline $\begin{array}{l}\text { Cui, } \\
2019 \text { (27) }\end{array}$ & $\begin{array}{l}\text { Prospective } \\
\text { cohort }\end{array}$ & SLIT & Children & $\begin{array}{l}\text { R w or } \\
\text { w/o A }\end{array}$ & $\begin{array}{l}2 \text { years, } 3 \text { drops of } \\
333 \mu \mathrm{g} / \mathrm{mL} \text { per day }\end{array}$ & CSMS & 60 & 31 & 29 & $\begin{array}{l}\text { Selection: }{ }^{* * *} \\
\text { comparability: } 0 \\
\text { Outcome: }{ }^{* *}\end{array}$ \\
\hline $\begin{array}{l}\text { Kim, } \\
2019^{(22)}\end{array}$ & $\begin{array}{l}\text { Retrospective } \\
\text { cohort }\end{array}$ & SLIT & $\begin{array}{l}\text { Children } \\
\text { and adults }\end{array}$ & $\begin{array}{l}\text { R w or } \\
\text { w/o A }\end{array}$ & $\begin{array}{l}2 \text { years, } 200 \text { STU } \\
\text { per day }\end{array}$ & TNSS & 68 & 16 & 52 & $\begin{array}{l}\text { Selection: }{ }^{* * *} \\
\text { comparability: } 0 \\
\text { Outcome: }{ }^{*}\end{array}$ \\
\hline $\begin{array}{l}\text { Zhang, } \\
2019^{(29)}\end{array}$ & $\begin{array}{l}\text { Retrospective } \\
\text { cohort }\end{array}$ & SLIT & Children & $\mathrm{R}$ & $\begin{array}{l}2 \text { years, } 3 \text { drops of } \\
333 \mu \mathrm{g} / \mathrm{mL} \text { per day }\end{array}$ & TNSS, TMS & 183 & 65 & 118 & $\begin{array}{l}\text { Selection: }{ }^{* * *} \\
\text { comparability: } 0 \\
\text { Outcome: }{ }^{* *}\end{array}$ \\
\hline
\end{tabular}

A, asthma; AIT, allergen-specific immunotherapy; AMS, anti-allergic medication score; AQLQ, asthma quality of life questionnaire; CSMS, combined symptom and medication score; RQLQ, Rhinoconjunctivitis Quality of Life Questionnaire; SCIT, subcutaneous immunotherapy; SLIT, sublingual immunotherapy; TMS, total medication score; TNSS, total nasal symptom score; TSS, total symptom score; VAS, visual analogue scale; SQ-U, standardized quality units. ¥Maximum score for each item in Newcastle-Ottawa Scale: selection, 0-4 stars; comparability, 0-2 stars; and outcome, 0-3 stars. 


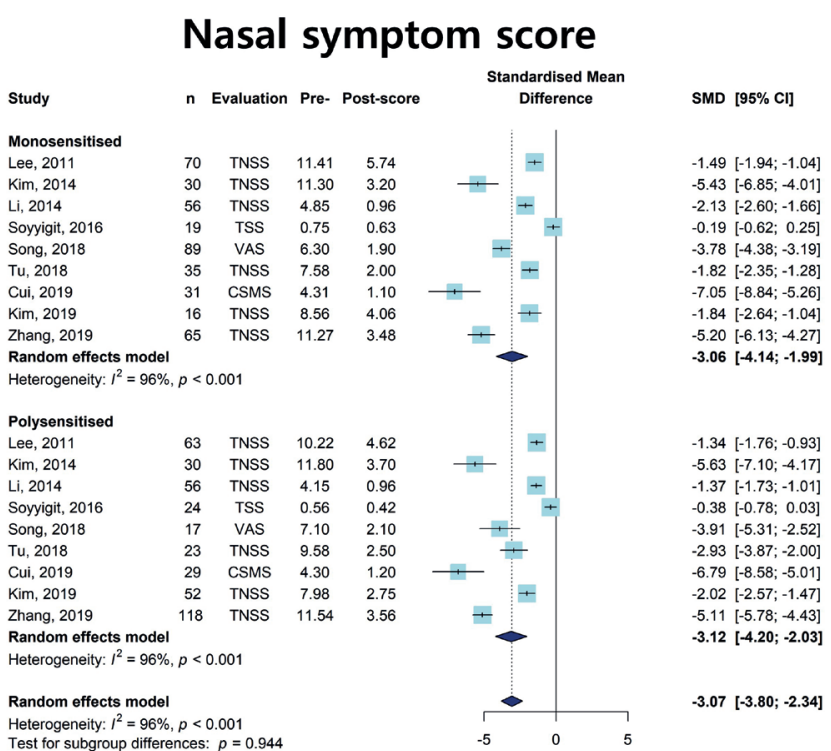

Figure 2. Comparison of the changes in nasal symptom score after single-allergen immunotherapy with HDM extract between monosensitised and polysensitised patients. Abbreviations: $\mathrm{Cl}$, confidence interval; $\mathrm{CSMS}$ combined symptom and medication score; HDM, house dust mite; TNSS, total nasal symptom score; TSS, total symptom score; SMD, standardised mean difference; VAS, visual analogue scale.

\section{Nasal symptom scores}

Nasal symptom score was assessed by total nasal symptom score (TNSS) in seven studies ${ }^{(21-24,26,28,29)}$, combined symptom medication score (CSMS) in one study ${ }^{(27)}$, and visual analogue scale (VAS) in one study ${ }^{(25)}$, respectively. There was a significant decrease in the nasal symptom score from pre-treatment to post-treatment in both monosensitised and polysensitised patients (SMD: $-3.06,95 \% \mathrm{Cl},-4.14$ to -1.99 and SMD: $-3.12,95 \%$ $\mathrm{Cl},-4.20$ to -2.03 in monosensitised and polysensitised patients, respectively; Figure 2) with a significant heterogeneity among the studies $\left(I^{2}=96 \% ; p<0.01\right.$ in both monosensitised and polysensitised patients). The change in nasal symptom score was not significantly different between the two groups $(p=0.944)$. In three ${ }^{(24,25,28)}$ out of nine studies, the baseline nasal symptom score in polysensitised patients was significantly higher than that in monosensitised patients. Therefore, we performed a sensitivity analysis omitting these three studies ${ }^{(24,25,28)}$. In the sensitivity analysis with six studies ${ }^{(21-23,26,27,29)}$, the clinical effectiveness of HDM AIT regarding nasal symptom score did not significantly differ between monosensitised and polysensitised patients (SMD: -3.68 versus -3.53 , respectively, $\mathrm{p}=0.876$; Figure 3 ), which is consistent with the result of the pooled analysis including all nine studies. A sensitivity analysis omitting each study is shown in Supplementary Table 1. Potential publication bias was evaluated using a funnel plot (Supplemental Figure 1). In Egger's test, there was no potential publication bias regarding

\section{Nasal symptom score}

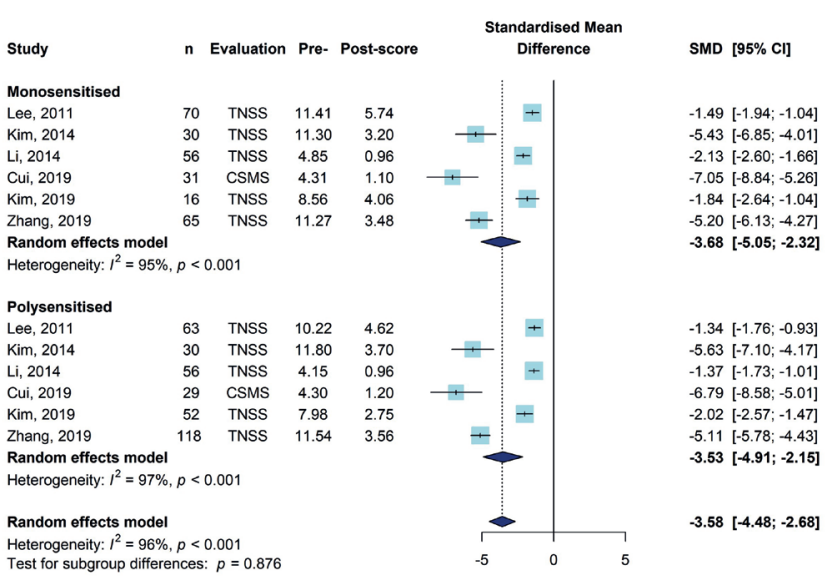

Figure 3. Sensitivity analysis for the comparison of the changes in nasal symptom score after single-allergen immunotherapy between monosensitised and polysensitised patients. Three studies in which the baseline nasal symptom score in polysensitised patients was significantly higher than that in monosensitised patients were omitted. Abbreviations: $\mathrm{Cl}$, confidence interval; CSMS, combined symptom and medication score; HDM, house dust mite; TNSS, total nasal symptom score; TSS, total symptom score; SMD, standardised mean difference; VAS, visual analogue scale.

the changes in nasal symptom score in monosensitised and polysensitised patients ( $p=0.144$ and $p=0.394)$.

\section{Medication scores}

Among nine studies, five ${ }^{(21,23,24,26,29)}$ investigated the clinical effectiveness in medication score in monosensitised and polysensitised patients. Four ${ }^{(21,24,26,29)}$ out of five studies were available for a pooled analysis; the mean and SD values of medication score was not obtainable in one study ${ }^{(23)}$. The pooled analysis showed that the change in medication score was not significantly different between monosenstised and polysensitised patients (SMD: -2.63 versus $-2.53, p=0.925$; Figure 4). The sensitivity analysis revealed the results when omitting each study were consistent with the results of the pooled analysis (Supplementary Table 2).

\section{Quality of life scores}

Among nine studies, three (24-26) evaluated the clinical improvement in Rhinoconjunctivitis Quality of Life Questionnaire (RQLQ) score between monosensitised and polysensitised patients. In a pooled analysis, the change in RQLQ score did not differ between monosenstised and polysensitised patients (SMD: -3.18 versus $-3.91, p=0.777$; Figure 5 ). The sensitivity analysis showed the results when omitting each study were consistent with the results of the pooled analysis (Supplementary Table 3). 


\section{Medication score}

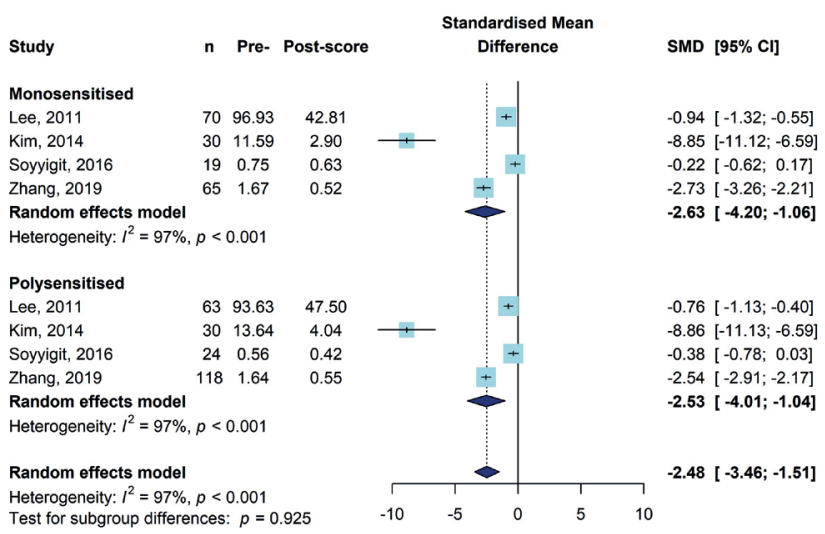

Figure 4. Comparison of the changes in medication score after singleallergen immunotherapy with HDM extract between monosensitised and polysensitised patients. Abbreviations: $\mathrm{Cl}$, confidence interval; HDM, house dust mite; SMD, standardised mean difference.

\section{Discussion}

AIT has been demonstrated to induce durable immunological modification in response to the specific allergen, through producing neutralising antibodies, through suppressing numbers and activity of allergen-specific Th2 cells and type 2 innate lymphoid cells, and by inducing regulatory T-cell activity ${ }^{(36,37)}$. The Global Allergy and Asthma European Network/European Academy of Allergy and Clinical Immunology (GA2LEN/EAACI) pocket guide suggests to consider AIT in patients with moderate-severe intermittent or persistent AR and rhinoconjunctivitis, especially those with insufficient response to pharmacotherapy, or those who wish to reduce or avoid long-term pharmacological therapy and its potential adverse effects ${ }^{(38)}$. Since AIT is a specific treatment modality that can change the immunological response to a single allergen or specific allergen component, the choice of allergen extract to use for polysensitised patients is open to debate ${ }^{(15)}$. In USA, AIT is commonly prescribed with all relevant allergens, and the SCIT extract preparations contain an average of eight different allergens ${ }^{(6)}$. However, the superiority of multiple-allergen AIT to single-allergen AIT is debatable. A previous systematic review demonstrated the clinical efficacy of multiple-allergen AIT but did not clearly show superiority of multiple-allergen AIT ${ }^{(18)}$. Furthermore, a previous randomised, double-blind, placebo-controlled study reported that SLIT with multiple-allergen extracts showed a limited response compared to that obtained using single-allergen extract, potentially limiting its use ${ }^{(39)}$. The GA2LEN/EAACl guidelines do no recommend mixtures ${ }^{\left({ }^{40}\right)}$. For grass pollen allergen, two large double-blind placebo-controlled clinical trials showed that the benefit of SLIT with single-allergen grass pollen in polysensitised patients was comparable to that in monosensitised patients ${ }^{(3,20)}$. However,

\section{Quality of life score}

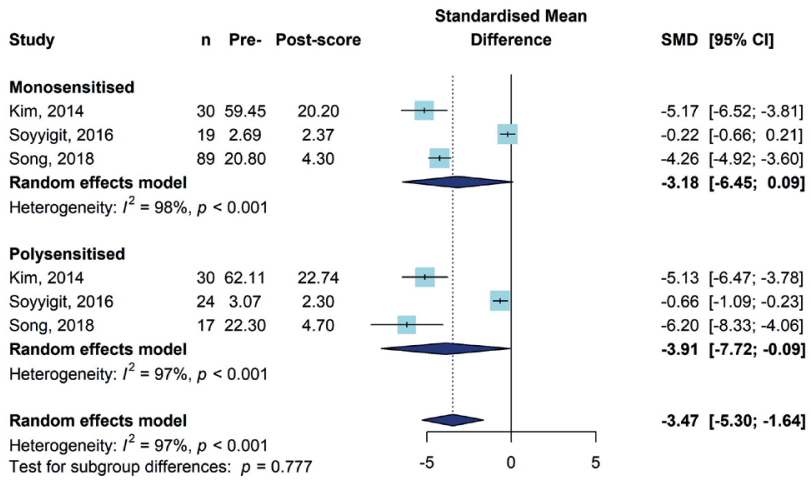

Figure 5. Comparison of the changes in medication score after singleallergen immunotherapy with HDM extract between monosensitised and polysensitised patients. Abbreviations: $\mathrm{Cl}$, confidence interval; HDM, house dust mite; SMD, standardised mean difference.

the supporting evidence of the clinical effectiveness of singleallergen AIT with HDM extracts in polysensitised patients compared to monosensitised patients is limited to observational studies ${ }^{(21-29)}$. Therefore, we conducted a systematic review and meta-analysis to integrate the evidence of clinical effectiveness of HDM AIT in polysensitised patients to make recommendations regarding the treatment of polysensitised patients. Nine studies were included in this systematic review and meta-analysis to compare clinical effectiveness of HDM AIT between monosensitised and polysensitised patients. All studies investigated nasal symptom or/and use of rescue medication and quality of life. Among the nine studies, seven ${ }^{(21,22,24-28)}$ were conducted on AR patients with or without asthma, the study of $\mathrm{Li}{ }^{(23)}$ was conducted on AR patients with asthma, while the study of Zhang ${ }^{(29)}$ was conducted on AR patients without asthma. AR was diagnosed according to guidelines, such as the Allergic Rhinitis and Its Impact on Asthma (ARIA) guideline ${ }^{(41)}$ in all individual studies except the study of Kim ${ }^{(26)}$ that did not report on the diagnosis of AR. In contrast, the diagnosis of asthma was based on the Global Initiative for Asthma (GINA) guideline (42) in two studies ${ }^{(23,24)}$, whereas, other studies did not report on the diagnosis of asthma; this may be explained by the fact that these studies focused on AR rather than asthma. The presence of significant improvement of clinical symptoms was evaluated before the comparison of clinical effectiveness. Out of nine studies, eight ${ }^{(21-23,25-29)}$ reported a significant clinical improvement in nasal symptom score after AIT from the baseline symptom in both the monosensitised and polysensitised groups, although high heterogeneity among the studies was found. In the study of Soyyigit ${ }^{(24)}$, although VAS score significantly decreased in the both groups, total symptom score significantly decreased in the polysensitised group but not in the monosensitised group. 
Considering the changes in nasal symptom scores after AIT, there was a severe heterogeneity in both the mono- and poly sensitised groups. This might be because of the different designs of the included studies. For example, the changes in nasal symptom score were the smallest in the study of Soyyigit ${ }^{(24)}$, in which the treatment duration of AIT was the shortest among the studies. In addition, the study of Cui ${ }^{(27)}$ showed the greatest changes in nasal symptom score, which might be caused by the different evaluation tools: CSMS. Because CSMS reflects medication and nasal symptom scores simultaneously, the changes in this value might be greater than the changes in other values such as TNSS.

Eight studies ${ }^{(21-23,25-29)}$ reported comparable improvement in nasal symptom score after HDM AIT in monosensitised and polysensitised patients, and one study ${ }^{(28)}$ reported greater clinical improvement in polysensitised patients than in monosensitised patients. Tu ${ }^{(28)}$ demonstrated a greater improvement in the polysensitised group than in the monosensitised group; the baseline nasal symptom score was higher in polysensitised patients than in monosensitised patients.

In the pooled analysis of nine studies, there was a significant decrease in the nasal symptom score in both groups; however, the changes were not significantly different between the two groups. A sensitivity analysis omitting three studies ${ }^{(24,25,28)}$ was performed to evaluate the effect of a potential confounding bias due to the difference in the baseline nasal symptom score between the two groups. However, the changes in nasal symptom score did not significantly differ between the two groups, which is consistent with the findings of pooled analysis including all studies. In addition, a sensitivity analysis omitting each study in turn revealed no significant differences between the two groups. The pooled analysis and sensitivity analysis found that the clinical effectiveness of HDM AIT in nasal symptom was comparable in monosensitised and polysensitised patients. One study compared the clinical effectiveness of HDM AIT between monosensitised and polysensitised groups with control groups; however, the inclusion criteria were not satisfied and the data for pooling were not extractable ${ }^{(43)}$. In the study of Nolte ${ }^{(43)}$, average total combined rhinitis symptom score improved by $17 \%$ and $18 \%$ compared to placebo groups in monosensitised and polysensitised groups, respectively. This was consistent our findings, which indicate comparable clinical effectiveness in monosensitised and polysensitised patients.

Five out of nine included studies ${ }^{(21,23,24,26,29)}$ assessed the clinical effectiveness in medication score in monosensitised and polysensitised patients. Four ${ }^{(21,23,26,29)}$ out of the five studies reported a significant improvement in medication score in the both groups; however, one study ${ }^{(24)}$ did not show a significant improvement in the both groups. In comparison of the clinical effectiveness in medication score between monosensitised and polysensitised patients, three studies ${ }^{(21,23,24,26)}$ demonstrated a comparable decrease in medication score between monosensitised and polysensitised patients; however, one study ${ }^{(29)}$ did not report whether a significant difference between monosensitised and polysensitised patients was present. In the pooled analysis, the changes in medication scores were comparable between the two groups. Three out of nine studies evaluated the clinical improvement in Rhinoconjunctivitis Quality of Life Questionnaire (RQLQ) score between monosensitised and polysensitised patients. Two ${ }^{(25,26)}$ out of the three studies demonstrated a significant improvement in RQLQ in the both groups. However, one study ${ }^{(24)}$ did not clearly demonstrate whether the improvement of RQLQ score was significant in the both groups. In comparison of the improvement in quality of life between monosensitised and polysensitised patients, all three studies ${ }^{(24-26)}$ showed comparable decrease in RQLQ score between monosensitised and polysensitised patients. In a pooled analysis, the changes in RQLQ score were comparable in the two groups.

There are some possible explanations for the comparable clinical effectiveness of HDM AIT between monosensitised and polysensitised patients. First, the difference between polysensitisation and polyallergic conditions may be related to the comparable clinical effectiveness: polysensitised patients are not necessarily polyallergic. To determine true polyallergy, medical history (e.g. the association between the sensitised allergens and the period during which the symptoms occur) may not be sufficient, and nasal challenge tests or component-based diagnostics are often needed; however, these tests are seldomly used in clinical settings ${ }^{(17)}$. Hence, although patients included in this systematic review were polysensitised, some patients may have had HDM as the only clinically relevant allergen. Second, HDMs play a major role in contributing to nasal symptoms, with the effect of other allergens being minor. Despite multiple clinically relevant allergens in each patient, not every allergen triggers an equivalent allergic response. In a previous study, we reported the lack of a significant correlation between the changes in the number of sensitised allergens and the changes in nasal visual analogue scale (VAS) score in children treated for 3 years with SLIT ${ }^{(36)}$, suggesting that allergens other than HDM do not have a significant effect on nasal symptoms. Therefore, single-allergen AIT with one clearly responsible allergen may have comparable clinical effectiveness.

The present study has some limitations. First, the clinical effectiveness of AIT in monosensitised and polysensitised patients was evaluated without control groups. Ideally, two pairs were needed for the design of this meta-analysis: monosensitised patients treated with AIT versus monosensitised patients treated with placebo, and polysensitised patients treated with AIT versus polysensitised patients treated with placebo. Although there are several controlled studies for AIT in monosensitised patients, no controlled study for AIT in only polysensitized patients was found. Therefore, we used the changes in nasal symptoms, 
medication, and quality of life scores from pre-treatment to post-treatment in monosensitised versus polysensitised patients from studies with results for both groups. Second, the clinically relevant allergen was not clearly demonstrated in several of the included studies. Among nine included studies, only four $(23,24,28,29)$ demonstrated clinical relevance for HDM sensitization in their inclusion criteria, whereas five ${ }^{(21,22,25-27)}$ merely described subjects as those with AR sensitized to HDM. As HDM plays a major role in countries where the individual studies were conducted, patients with AR sensitized to HDM may have a clinically relevant HDM allergy. However, confirming the clinical relevance is very important before starting AIT. Furthermore, only two studies demonstrated clinical relevance for allergens other than HDM, which suggests that some polysensitised patients might not be polyallergic. Therefore, patients who are not true polyallergic might contribute to the comparable clinical effectiveness of HDM AIT between monosensitised and polysensitised patients.

To the best of our knowledge, this is the first systematic review and meta-analysis to compare the clinical effectiveness of single-allergen AIT with HDM extracts in monosensitised and polysensitised patients. Despite its limitations, we believe this study may provide supporting evidence and rationale for single-allergen AIT for indications other than grass pollen in polysensitised patients. However, to validate the clinical effectiveness of HDM AIT in polysensitised patients, further investigation is warranted. First, it is necessary to compare the clinical effectiveness of HDM AIT in clinically relevant monosensitised and polysensitised patients in well-powered randomised, placebo-controlled studies.
In addition, further research should be performed to compare the clinical effectiveness of single-allergen AIT with HDM extract and multiple-allergen AIT. For grass pollen, two well-designed studies ${ }^{(18,44)}$ compared single-allergen AIT and multiple-allergen AIT in polysensitised patients; however, there was a discrepancy between the findings of the two studies. For HDM, there is a lack of well-design studies comparing single-allergen AIT and multiple-allergen AIT in polysensitised patients.

\section{Conclusion}

In conclusion, single-allergen AIT with HDM extracts showed similar clinical effectiveness in polysensitised and monosensitised patients. Although well-designed and well-powered studies are required to validate the clinical effectiveness of HDM AIT in polysensitised patients, clinicians may consider administering HDM AIT in AR patients polysensitised to HDM and other allergens in countries where HDM plays a major role as a dominant allergen.

\section{Authorship contribution}

Acquisition of data: JYK, $\mathrm{DHH}$; analysis and interpretation of data: JYK, DYH, MJJ; drafting the manuscript for critical intellectual content: JYK, MJJ; review and improvement of the manuscript: DHH, CSR; conception and design of the study: JYK, DHH.

\section{Conflict of interest}

All authors had no conflict of interest on this study.

\section{Financial disclosure}

None

\section{References}

1. Wilson DR, Lima MT, Durham SR. Sublingual immunotherapy for allergic rhinitis: systematic review and meta-analysis. Allergy. 2005 60(1): 4-12.

2. Compalati E, Passalacqua G, Bonini M Canonica GW. The efficacy of sublingual immunotherapy for house dust mites respiratory allergy: results of a GA2LEN metaanalysis. Allergy. 2009; 64(11): 1570-1579.

3. Nelson H, Blaiss M, Nolte H, Wurtz SO Andersen JS, Durham SR. Efficacy and safety of the SQ-standardized grass allergy immunotherapy tablet in mono- and polysensitized subjects. Allergy. 2013; 68(2): 252-255.

4. Bernstein DI, Murphy KR, Nolte H, Kaur A, Maloney J. Efficacy of short-ragweed sublingual immunotherapy tablet MK-3641 in monosensitized and polysensitized subjects. Allergy, Asthma Clin Immunol. 2014; 10(Suppl 2): A31.

5. Di Bona D, Plaia A, Leto-Barone MS, La Piana S, Di Lorenzo G. Efficacy of subcutaneous and sublingual immunotherapy with grass allergens for seasonal allergic rhinitis: a meta-analysis-based comparison. J Allergy Clin Immunol. 2012; 130(5): $1097-$

\section{7 e1092.}

6. Damask C. Immunotherapy: Treating with Fewer Allergens? Otolaryngol Clin North Am. 2017; 50(6): 1153-1165.

7. Demoly P, Passalacqua G, Pfaar O, Sastre J, Wahn U. Management of the polyallergic patient with allergy immunotherapy: a practice-based approach. Allergy Asthma Clin Immunol. 2016; 12: 2

8. Pepper AN, Calderon MA, Casale TB. Sublingual Immunotherapy for the Polyallergic Patient. J Allergy Clin Immunol Pract. 2017; 5(1): 41-45.

9. Wahn U. Allergen immunotherapy for the polyallergic patient. Curr Opin Allergy Clin Immunol. 2016; 16(6): 571-575.

10. Bahceciler NN, Galip N, Cobanoglu N. Multiallergen-specific immunotherapy in polysensitized patients: where are we? Immunotherapy. 2013; 5(2): 183-190.

11. Bousquet J, Lockey R, Mailing $H$, et al. Allergen immunotherapy: therapeutic vaccines for allergic diseases. Ann Allergy, Asthma Immunol. 1998; 81(5 I): 401-405.

12. Crimi N, Li Gotti F, Mangano G, et al. A randomized, controlled study of specific immunotherapy in monosensitized subjects with seasonal rhinitis: effect on bronchial hyperresponsiveness, sputum inflammatory markers and development of asthma symptoms. Ann Ital Med Int. 2004; 19(2): 98-108.

13. Yukselen A, Kendirli SG, Yilmaz M, Altintas DU, Karakoc GB. Two year follow-up of clinical and inflammation parameters in children monosensitized to mites undergoing subcutaneous and sublingual immunotherapy. Asian Pac J Allergy Immunol. 2013; 31(3): 233.

14. Ciprandi G, Cirillo I. Monosensitization and polysensitization in allergic rhinitis. Eur J Int Med. 2011; 22(6): e75-79.

15. Passalacqua $\mathrm{G}$. The use of single versus multiple antigens in specific allergen immunotherapy for allergic rhinitis: review of the evidence. Curr Opin Allergy Clin Immunol. 2014; 14(1): 20-24.

16. Cox L, Jacobsen L. Comparison of allergen immunotherapy practice patterns in the United States and Europe. Ann Allergy, Asthma Immunol. 2009; 103(6): 451-460.

17. Migueres M, Dávila I, Frati F, et al. Types of sensitization to aeroallergens: definitions, prevalences and impact on the diagnosis and treatment of allergic respiratory dis- 
ease. Clin Translat Allergy. 2014; 4(1): 1-8.

18. Nelson HS. Multiallergen immunotherapy for allergic rhinitis and asthma. J Allergy Clin Immunol. 2009; 123(4): 763-769.

19. Hrubiško M, Špicák V. Allergen immunotherapy in polysensitized patient. Eur Ann Allergy Clin Immunol. 2016; 48: 69-76.

20. Malling HJ, Montagut A, Melac M, et al. Efficacy and safety of 5-grass pollen sublingual immunotherapy tablets in patients with different clinical profiles of allergic rhinoconjunctivitis. Clinical \& Experimental Allergy. 2009; 39(3): 387-393.

21. Lee JE, Choi YS, Kim MS, et al. Efficacy of sublingual immunotherapy with house dust mite extract in polyallergen sensitized patients with allergic rhinitis. Ann Allergy Asthma Immunol. 2011; 107(1): 79-84.

22. Kim JY, Han DH, Won TB, et al. Immunologic modification in mono- and poly-sensitized patients after sublingual immunotherapy. Laryngoscope. 2019; 129(5): E170-E177.

23. Li P, Li Q, Huang Z, Chen W, Lu Y, Tian M. Efficacy and safety of house dust mite sublingual immunotherapy in monosensitized and polysensitized children with respiratory allergic diseases. Int Forum Allergy Rhinol. 2014; 4(10): 796-801.

24. Soyyigit S, Guloglu D, Ikinciogullari A, et al. Immunologic alterations and efficacy of subcutaneous immunotherapy with Dermatophagoides pteronyssinus in monosensitized and polysensitized patients. Ann Allergy Asthma Immunol. 2016; 116(3): 244251 e242.

25. Song Y, Long J, Wang T, Xie J, Wang M, Tan G. Long-term efficacy of standardised specific subcutaneous immunotherapy in children with persistent allergic rhinitis due to multiple allergens including house dust mites. J Laryngol Otol. 2018; 132(3): 230235.

26. Kim SH, Shin SY, Lee KH, Kim SW, Cho JS Long-term Effects of Specific Allergen Immunotherapy Against House Dust Mites in Polysensitized Patients With Allergic Rhinitis. Allergy Asthma Immunol Res. 2014 6(6): 535-540

27. Cui L, Li J, Li Y, Xia Z. Long-Term Efficacy of Sublingual Mite Immunotherapy in Monosensitized and Polysensitized Children with Allergic Rhinitis: A 7-Year Prospective Study. Int Arch Allergy Immunol. 2019;
180(2): 144-149

28. Tu Y, Zhang $H$, Zhao $L$, et al. The changes in different symptom scores during subcutaneous immunotherapy in Chinese house dust mite allergic patients: a two-year observational study. J Laryngol Otol. 2019; 133(3): 213-219

29. Zhang YZ, Luo J, Wang ZH, Wang J. Efficacy and safety of sublingual dust mite drops in children with mono- or polysensitized allergic rhinitis. Am J Otolaryngol. 2019; 40(5): 755-760.

30. Moher D, Liberati A, Tetzlaff J, Altman DG, Group P. Preferred reporting items for systematic reviews and meta-analyses: the PRISMA statement. PLoS med. 2009; 6(7): e1000097.

31. Peterson J, Welch V, Losos M, Tugwell P. The Newcastle-Ottawa scale (NOS) for assessing the quality of nonrandomised studies in meta-analyses. Ottawa: Ottawa Hospital Research Institute. 2011.

32. Wan X, Wang W, Liu J, Tong T. Estimating the sample mean and standard deviation from the sample size, median, range and/or interquartile range. BMC Med Res Methodol. 2014; 14(1): 135.

33. Higgins JP, Thomas J, Chandler J, et al Cochrane handbook for systematic reviews of interventions: John Wiley \& Sons; 2019.

34. Abrams KR, Gillies CL, Lambert PC. Metaanalysis of heterogeneously reported trials assessing change from baseline. Stat Med. 2005; 24(24): 3823-3844

35. Zwetsloot P-P, Van Der Naald M, Sena ES, et al. Standardized mean differences cause funnel plot distortion in publication bias assessments. Elife. 2017; 6: e24260.

36. Hammad H, Lambrecht BN. Barrier Epithelial Cells and the Control of Type 2 Immunity. Immunity. 2015; 43(1): 29-40.

37. Hesse L, van leperen $N$, Habraken C, et al. Subcutaneous immunotherapy with purified Der $\mathrm{p} 1$ and 2 suppresses type $2 \mathrm{immu}$ nity in a murine asthma model. Allergy. 2018; 73(4): 862-874.

38. Zuberbier T, Bachert C, Bousquet PJ, et al. GA2LEN/EAACl pocket guide for allergenspecific immunotherapy for allergic rhinitis and asthma. Allergy. 2010; 65(12): 15251530

39. Amar SM, Harbeck RJ, Sills M, Silveira LJ, O'Brien H, Nelson HS. Response to sub- lingual immunotherapy with grass pollen extract: monotherapy versus combination in a multiallergen extract. J Allergy Clinical Immunol. 2009: 124(1): 150-156. e155.

40. Zuberbier $T$, Bachert $C$, Bousquet $P$, et al. GA2LEN/EAACI pocket guide for allergenspecific immunotherapy for allergic rhinitis and asthma. Allergy. 2010; 65(12): 15251530

41. Bousquet J, Khaltaev N, Cruz AA, et al. Allergic Rhinitis and its Impact on Asthma (ARIA) 2008 update (in collaboration with the World Health Organization, GA(2)LEN and AllerGen). Allergy. 2008; 63 Suppl 86: 8-160.

42. Global Initiative For Asthma. GINA Report, Global Strategy for Asthma management and Prevention-2010. http://www.ginasthma.org/.

43. Nolte H, Bernstein DI, Nelson HS, et al. Efficacy of house dust mite sublingual immunotherapy tablet in North American adolescents and adults in a randomized, placebo-controlled trial. J Allergy Clinical Immunol. 2016; 138(6): 1631-1638.

44. Marogna M, Spadolini I, Massolo A, et al. Effects of sublingual immunotherapy for multiple or single allergens in polysensitized patients. Ann Allergy Asthma Immunol. 2007; 98(3): 274-280.

Doo Hee Han, MD, PhD

Associate Professor

Department of Otorhinolaryngology

Seoul National University College of

Medicine

101 Daehak-ro

Jongno-gu

Seoul 03080

Korea

Tel: $+82-2-2072-4038$

Fax: +82-2-766-2447

E-mail: handh@snu.ac.kr 


\section{SUPPLEMENTARY MATERIAL}

A

\section{Monosensitised patients}

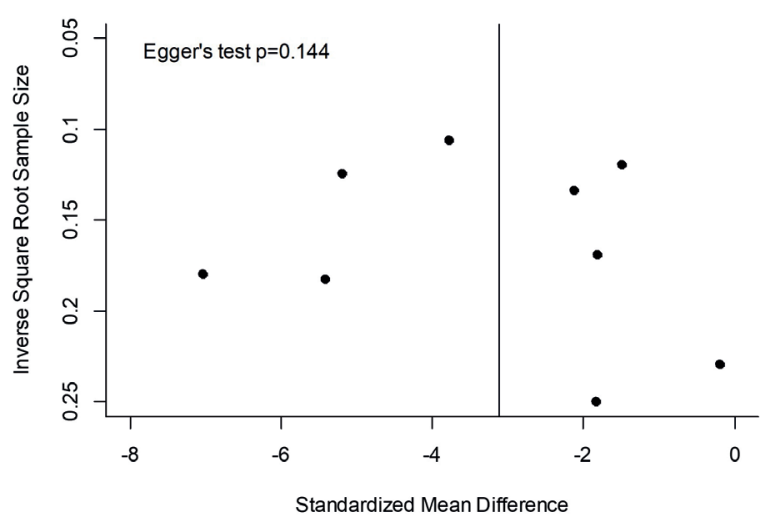

B

Polysensitised patients

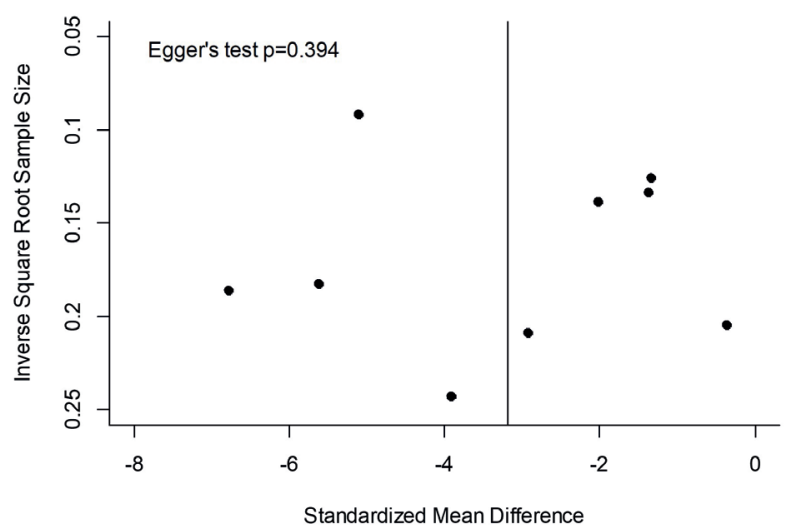

Supplementary Figure 1. Funnel plot of changes in nasal symptom score after single-allergen immunotherapy in (A) monosensitised and (B) polysensitised patients. Abbreviation: HDM, house dust mite.

Supplementary Table 1. Sensitivity analysis for the comparison of changes in nasal symptom score after single-allergen immunotherapy between monosensitised and polysensitised patients.

\begin{tabular}{|llll}
\hline & Monosensitised & Polysensitised & $\begin{array}{c}\text { Test for subgroup difference } \\
\text { (p value) }\end{array}$ \\
\hline Overall & $-3.06(-4.14,-1.99)$ & $-3.12(-4.20,-2.30)$ & 0.940 \\
\hline Omitting Lee, 2011 & $-3.30(-4.58,-2.02)$ & $-3.39(-4.70,-2.08)$ & 0.921 \\
\hline Omitting Kim, 2014 & $-2.79(-3.87,-1.70)$ & $-2.82(-3.91,-1.74)$ & 0.964 \\
\hline Omitting Li, 2014 & $3.22(-4.50,-1.94)$ & $-3.40(-4.75,-2.04)$ & 0.850 \\
\hline Omitting Soyyigit, 2016 & $-3.41(-4.42,-2.40)$ & $-3.49(-4.64,-2.34)$ & 0.920 \\
\hline Omitting Song, 2016 & $-2.96(-4.07,-1.85)$ & $-3.02(-4.16,-1.89)$ & 0.934 \\
\hline Omitting Tu, 2018 & $-3.25(-4.50,-2.00)$ & $-3.14(-4.31,-1.97)$ & 0.904 \\
\hline Omitting Cui, 2019 & $-2.66(-3.71,-1.60)$ & $-2.73(-3.80,-1.66)$ & 0.919 \\
\hline Omitting Kim, 2019 & $-3.23(-4.42,-2.04)$ & $-3.29(-4.54,-2.04)$ & 0.947 \\
\hline Omitting Zhang, 2019 & $-2.76(-3.80,-1.73)$ & $-2.75(-3.66,-1.84)$ & 0.984
\end{tabular}

The values present standardised mean difference ( $95 \%$ confidence interval) for the nasal symptom scores between pre- and post-treatment.

Supplementary Table 2. Sensitivity analysis for the comparison of clinical effectiveness of single-allergen immunotherapy in medication score between monosensitised and polysensitised patients.

\begin{tabular}{|lllc|}
\hline & Monosensitised & Polysensitised & $\begin{array}{c}\text { Test for subgroup difference } \\
\text { ( } \mathbf{p} \text { value) }\end{array}$ \\
\hline Overall & $-2.63(-4.20,-1.06)$ & $-2.53(-4.01,-1.04)$ & 0.925 \\
\hline Omitting Lee, 2011 & $-3.59(-6.27,-0.91)$ & $-3.46(-5.73,-1.18)$ & 0.941 \\
\hline Omitting Kim, 2014 & $-1.29(-2.60,0.03)$ & $-1.23(-2.54,0.08)$ & 0.952 \\
\hline Omitting Soyyigit, 2016 & $-3.71(-5.93,-0.49)$ & $-3.49(-5.49,-1.49)$ & 0.882 \\
\hline Omitting Zhang, 2019 & $-2.53(-4.28,-0.78)$ & $-2.46(-4.13,-0.79)$ & 0.955
\end{tabular}

The values present standardised mean difference ( $95 \%$ confidence interval) for the medication score between pre- and post-treatment. 
Supplementary Table 3. Sensitivity analysis for the comparison of clinical effectiveness of single-allergen immunotherapy in quality-of-life score between monosensitised and polysensitised patients.

\begin{tabular}{|llcc|}
\hline & Monosensitised & Polysensitised & $\begin{array}{c}\text { Test for subgroup difference } \\
\text { ( } \mathbf{p} \text { value) }\end{array}$ \\
\hline Overall & $-3.18(-6.45,0.09)$ & $-3.91(-7.72,-0.09)$ & 0.777 \\
\hline Omitting Kim, 2014 & $-2.23(-6.19,1.72)$ & $-3.33(-8.75,2.10)$ & 0.750 \\
\hline Omitting Soyyigit, 2016 & $-4.51(-5.31,-3.71)$ & $-5.43(-6.57,-4.29)$ & 0.195 \\
\hline Omitting Song, 2018 & $-2.65(-7.49,2.19)$ & $-2.85(-7.22,1.53)$ & 0.953 \\
\hline
\end{tabular}

The values present standardised mean difference ( $95 \%$ confidence interval) for the quality-of-life score between pre- and post-treatment. 